\title{
Trustworthiness of digital government services: deriving a comprehensive theory through interpretive structural modelling
}

\section{Marijn Janssen, Nripendra P. Rana, Emma L. Slade \& Yogesh K. Dwivedi}

To cite this article: Marijn Janssen, Nripendra P. Rana, Emma L. Slade \& Yogesh K. Dwivedi (2018) Trustworthiness of digital government services: deriving a comprehensive theory through interpretive structural modelling, Public Management Review, 20:5, 647-671, DOI: 10.1080/14719037.2017.1305689

To link to this article: https://doi.org/10.1080/14719037.2017.1305689
(c) 2017 The Author(s). Published by Informa UK Limited, trading as Taylor \& Francis Group

Submit your article to this journal $₫$

View related articles
Published online: 31 Mar 2017.

Џ Article views: 3259

View Crossmark data $\$ 


\title{
Trustworthiness of digital government services: deriving a comprehensive theory through interpretive structural modelling
}

\author{
Marijn Janssen (iD) ${ }^{a}$ Nripendra P. Rana ${ }^{b}, E^{2 m m a ~ L . ~ S l a d e ~}{ }^{b}$ \\ and Yogesh K. Dwivedib
}

aFaculty of Technology, Policy, \& Management, Delft University of Technology, Delft, The

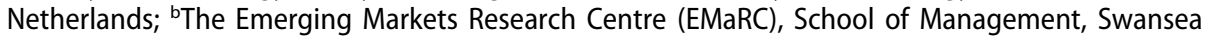
University, Swansea, UK

\begin{abstract}
Having its origin in public administration, trustworthiness is a significant concept in digital government research, influencing the relationships between citizens and governments. However, the interrelationships between the facets of trustworthiness are given inadequate attention. Therefore, the aim of this research was to develop a theory detailing the factors affecting citizens' perceptions of e-government trustworthiness. A comprehensive review of public administration and information systems literature highlighted 20 pertinent variables. The interrelationships of these variables were identified and categorized according to their driving and dependence power by employing interpretive structural modelling. The proposed model was then drawn based on the level partitioning of variables and interrelationships of the variables determined using the final reachability matrix. The findings reveal that current conceptualizations of digital government trustworthiness take a too narrow view. The findings can help government policy makers with understanding the interrelated factors associated with trustworthiness in the context of digital government services and implement them in effective strategic planning.
\end{abstract}

KEYWORDS Trustworthiness; trust; electronic government; digital government; ISM; theory; Citizens

\section{Introduction}

Governments are struggling with their relationships with the public. Studies have shown that the trust of citizens in government has declined dramatically over recent decades (e.g. Hibbing and Theiss-Morse 2001; Rosenstone and Hansen 1993). Digital government - or e-government - technologies are regarded as key to improving relationships between government and the public (Morgeson III et al., 2011; Ravishankar 2013; Shareef et al. 2016a). Some regard e-government as a powerful tool for improving the internal efficiency of the government, the quality of service delivery, and public participation and engagement (Dwivedi et al., 2016a; Dawes 2008; Gil-García and Pardo 2005; Parent, Vandebeek, and Gemino 2005; Rana and Dwivedi 2015; Rana et al. 2015a, 2016). Others find e-government to be a means of helping to establish trustworthy institutions and building or restoring citizen's trust 
in government (Bellamy and Taylor 1998; Tolbert and Mossberger 2006; West 2005; Sandeep and Ravishankar 2014).

Trust is important in the e-services context to help users overcome perceptions of uncertainty and risk (McKnight, Choudhury, and Kacmar 2002), which may inhibit citizens' use of e-government technologies. Although scholars in the public administration field have discussed the significance of trust (e.g. Behn 1995; Nachmias 1985; Ruscio 1996), not much empirical research on this subject is yet found (Cho and Poister 2013). Originating in the public administration literature, trustworthiness has become central to e-government research (Carter and Belanger 2005; Welch, Hinnant, and Moon 2005). The concept of trustworthiness refers to the properties through which a trusted entity (whether another person or an institution) serves the interests of the trustor (citizen or business) (Levi and Stoker 2000). Belanger, Hiller, and Smith (2002) defined trustworthiness as the perception of conviction in the trusted entity's reliability and integrity. This perception usually involves concerns related to security and privacy.

Despite its importance for the e-government context (Das, DiRienzo, and Burbridge 2010), causality of trust in governance remains an under-investigated area (Vigoda-Gadot and Yuval 2003). Carter and Belanger (2005) recommend further research into the specific components of e-government trustworthiness. Although Yang and Anguelov (2013) provide comprehensive preliminary discussions of factors contributing to the trustworthiness of public services, public sector literature has not yet holistically considered the factors affecting citizens' perceptions of e-government trustworthiness.

The interpretive structural modelling (ISM) method helps to impose order and direction on the complexity of the relationships among the variables of a system (Sage 1977). Therefore, the aim of this research is to conduct ISM to develop a theory detailing the factors affecting citizens' perceptions of e-government trustworthiness. By doing so, this work will attempt to answer the following research question: which factors affect citizens' perceptions of e-government trustworthiness and how are they related to each other? The research endeavours to make a cross-disciplinary contribution through application of knowledge from public sector, e-government, and information systems literature. We limit the scope of e-government to government-to-citizen e-government transactional and interactional services in accordance with other researchers (e.g. Lee and Rao 2009; Shareef et al. 2011).

The remainder of the paper is as follows. First, a literature review of public administration and information systems research uncovers a variety of factors linked to e-government trustworthiness. In the next section, the ISM method employed to determine the power of the antecedents is described. In the further sections, the results and their implications are discussed. Finally, the paper is concluded, outlining limitations and suggestions for future research.

\section{Literature review}

Trust and trustworthiness are fundamentally distinct but closely related concepts (Yang and Anguelov 2013). Cho and Lee (2011) discuss the differences between trust and trustworthiness at length, determining that trustworthiness centres around the characteristics of a trustee whereas trust concerns a trustor's psychological state. 
Therefore, trust is an individual's perception of the trustworthiness owned or displayed by another (Grimmelikhuijsen and Meijer 2014; Yang and Anguelov 2013).

In contrast to the context of e-commerce, there are unlikely to be competing e-government services, making trust even more vital to prevent citizens reverting to traditional offline interactions with government (Teo, Srivastava, and Jiang 2008). Cho and Lee (2011) argue that focussing on the trustworthiness rather than on trust is more practically useful in order to guide public managers' trust-building activities. In a similar vein, Yang and Anguelov (2013) argue that trustworthiness can be directly controlled or influenced by public sector managers and decision makers.

There have been two overarching focal points in terms of trustors in public administration research: public sector servants and citizens. Considering the former, existing research has explored the role of perceived trustworthiness as a managerial resource within US federal agencies (Cho and Lee 2011), the role of trust in public servants' organizational identification (Campbell and Im 2015), and the effects of different types of trust on employee satisfaction and organizational commitment (Cho and Park 2011). Focussing on citizens as the trustors, public sector research has explored the effect of e-government adoption and/or satisfaction on citizens' trust in government (e.g. Hong 2013; Morgeson, VanAmburg, and Mithas 2011; Welch, Hinnant, and Moon 2005), the effect of transparency on citizens' perceptions of trustworthiness (Grimmelikhuijsen and Meijer 2014), and the role of organizational politics and ethics as predictors of citizens' trust in governance (Vigoda-Gadot 2007).

Even though gaining citizens' trust is a high priority for public organizations (Park and Blenkinsopp 2011), Robinson et al. (2013) argue that limited work has been conducted to examine the factors contributing to citizens' perceptions of trustworthiness of specific agencies, programmes, or services and find that models of trust need to be specific to the context. Most theory and empirical research on the impact of e-government on citizens' trust in government remains at the macro-level and misses out on the deeper understanding of the interaction between the factors directly or indirectly influencing the trustworthiness of e-government (Smith 2010, 2011). This lack of empirical data is partially due to the relatively contemporary nature of e-government implementation that has meant limited time and opportunities to study the wider social, economic, and political implications of e-government projects (Weare 2002).

\section{Trustworthiness of e-government and associated variables}

Trustworthiness of e-government is based on characteristics of e-government that may generate citizens' trust. Mayer, Davis, and Schoorman (1995) identified three core dimensions of trustworthiness: ability, benevolence, and integrity. These three principles are associated with competence, good intentions, and honesty and consistency, respectively (see McKnight, Choudhury, and Kacmar 2002; Yang and Anguelov 2013). A number of public sector studies have employed these dimensions of trustworthiness in government and e-government (e.g. Cho and Lee 2011; Grimmelikhuijsen and Meijer 2014; Shareef, Archer, and Dwivedi 2015; Yang and Anguelov 2013). Despite criticisms of adopting unidimensional scales of trust, other studies have captured trustworthiness as a unidimensional scale (e.g. Park and Blenkinsopp 2011), sometimes even using just one of the three aforementioned dimensions as a measure of trustworthiness (e.g. Robinson et al. 2013). 
Lee and Rao (2009) focus on 'trust in e-government agent', measuring benevolence, integrity, and competence beliefs as reflective indicators of a second-order construct, whereas Tan, Benbasat, and Cenfetelli (2008) model competence, integrity, and benevolence as predictors of customer trust. Dashti, Benbasat, and Burton-Jones (2009) argue that citizens' trust in e-government reflects their evaluation of the officials responsible for developing, maintaining, and monitoring the system rather than the system itself. This suggests that the dimensions of trustworthiness, that is, ability, benevolence, and integrity, are relevant for e-government. However, Dashti, Benbasat, and Burton-Jones (2009) include trustworthiness as a measurement item of the latent variable 'trust in e-government.' Teo, Srivastava, and Jiang (2008) modelled trust in government and trust in Internet as predictors of trust in e-government website. Carter and Belanger (2005) proposed a model of e-government trustworthiness comprised trust of the Internet and trust of government, but cross-loading led to the combination of the observed variables to form one trustworthiness construct. These various measurements and conceptualizations demonstrate the inconsistency in the use of 'trust' and 'trustworthiness' as constructs in e-government research.

Given that citizens hold the government accountable when services provided by third parties go wrong, Yang and Anguelov (2013) argue that trust in government is inextricably linked to trustworthiness of public services, which implies that trust in government is linked to trustworthiness of e-government. Dashti, Benbasat, and Burton-Jones (2009) differentiate trust in government and trust in e-government by the visibility of the public servants and their direct contact with the public. They found support for their hypothesis that trust in government would positively affect trust in e-government, suggesting that citizens' rely partly on their offline experience with public servants to evaluate their less visible counterparts who operate e-government; if government behaves sincerely offline, then it appears that citizens are more likely to believe that e-government will behave similarly. These findings are in line with Vigoda-Gadot \& Yuval's (2003, p.504) arguments that 'as customers of public services, citizens tend to generalize their attitudes.'

In addition to trust in government, Belanger and Carter (2008) propose that initial trust in e-government is composed of trust of the Internet as the enabling technology of e-government services and find that both of these constructs significantly affect intention to use e-government services. However, when modelled as predictors of trust in e-government website, trust in technology was only found to be a significant predictor for active users (Teo, Srivastava, and Jiang 2008), evidencing a contextual effect of trust of the Internet.

E-government provides a vehicle for increased dissemination of information and hence improved transparency. Transparency has been found to increase citizens' trust in local government (e.g. Tolbert and Mossberger 2006) as well as being a predictor of trust and satisfaction (Park and Blenkinsopp 2011). However, Grimmelikhuijsen and Meijer (2014) found that prior knowledge and disposition to trust government moderated the relationship between transparency and perceived trustworthiness, suggesting that the link between transparency and trustworthiness is more complicated. Although much of the empirical evidence suggests transparency is an antecedent of trustworthiness, Margetts (2011) makes an interesting point about the limits of transparency and potential detrimental effects of highlighting incompetence as a result of transparency. This suggests that presenting wrong or inaccurate 
information as a result of transparency may negatively affect trustworthiness of e-government.

Citizens want to know that public servants are listening and will respond to their needs (Ravishankar 2013; Yang and Anguelov 2013) and interaction between two parties helps to develop trust (see Welch, Hinnant, and Moon 2005). Responsiveness relates to perceptions about the willingness of a service provider to help the customer and can positively affect customer trust (Gefen 2002). E-government websites create opportunities for convenient and quick interactions between citizens and public servants (Tolbert and Mossberger 2006). Responsiveness of public servants behind the e-government system may make a citizen feel cared about by the government, which may increase perceptions of trustworthiness. Tolbert and Mossberger (2006) found that responsiveness was directly linked to increased trust of local government. Tan, Benbasat, and Cenfetelli (2008) found responsiveness to be a core attribute of service quality, concluding that such a feature is central to e-government service design. The finding of Welch et al. (2005) - that individuals with more concern about the responsiveness of government are less satisfied - suggests an important relationship between responsiveness and satisfaction with e-government.

Welch, Hinnant, and Moon (2005) argue that factors such as accountability may be just as important as concerns over the technical systems enabling e-government services. 'To be accountable is to provide information about one's performance, to take corrective action as necessary, and to be responsible for one's performance' (Wang and Wan Wart 2007, p.270), suggesting that transparency and responsiveness are inextricably linked to accountability. Although accountability is influenced by information quality, information asymmetry blurs insight. Baldwin, Gauld, and Goldfinch (2012) explored public servant attitudes towards ICT and e-government in New Zealand. Using a mixture of closed- and open-ended questions, it was revealed that while some of the 240 respondents saw increased accountability as a result of e-government, others envisaged the opposite. From the citizen perspective, accountability as a result of e-government may precede trustworthiness of e-government (see Sandeep and Ravishankar 2014).

Privacy and security relate to the safety of information (Shareef et al. 2016b; Teo, Srivastava, and Jiang 2008). Transactional services require citizens to disclose personal information before a transaction can be completed (Beldad et al. 2012); thus, 'privacy and security are reoccurring issues in e-commerce and e-government research' (Carter and Belanger 2005, p.9). Perceived privacy and security of information is critical to instil users' confidence. Asgarkhani's (2005) report on a pilot study of a digital government project in New Zealand documented concerns about data security and confidentiality with regard to online government services. For both experienced and inexperienced users, confidence in online privacy statements has been found to be very important in predicting trust in e-government (Beldad et al. 2012). Shareef et al. (2011) also found that beliefs in security contribute to developing trust in e-government.

Spatial separation when conducting transactions via e-government also involves an element of risk from sources of attack such as third-party hacking. Perceived risk is related to the uncertain outcome of a behaviour (Lee and Rao 2009). Evidence of the relationship between perceived risk and trust in e-government remains largely convoluted. Belanger and Carter (2008) found trust of the government, but not trust of the Internet, to have a significant negative effect on perceived risk of e-government 
services, and that perceived risk had a negative effect on intention to use e-government. Horst, Kuttschreuter, and Gutteling (2007) found perceived risk of e-services to negatively affect trust in e-government. Unusually, Shareef et al. (2011) found perceived uncertainty to have a positive effect on trust, which they argued was a result of the respondents' enjoyment of the virtual characteristics of e-government in the presence of security and technical ability.

In the context of e-government services, system quality is a subjective assessment of the e-government website. Lee and Rao (2009) found that website quality has a significant effect on citizens' confidence in the competence of an e-government service provider. Among respondents with e-government experience, it has been found that the quality of previous online government transactions plays an important role in shaping trust in government (Beldad et al. 2012). Another measure of perceived quality, service quality is a subjective assessment of a service received against expectations of that service (Parasuraman, Zeithaml, and Berry 1988; Shareef et al. 2014). Carter and Belanger (2005) argue that those who have a positive experience of e-government services will be more likely to use the service again. Parent, Vandebeek, and Gemino (2005) found e-government service quality to have a significant effect on trust in government. Tan, Benbasat, and Cenfetelli (2008) also found service quality to highly influence the three core constructs of trustworthiness. In the opposite direction, Teo, Srivastava, and Jiang (2008) found trust in e-government website to significantly predict both system quality and service quality. The meta-analysis of Rana et al. (2015b) found support of the significant effects of system and service quality on satisfaction, which has also been confirmed in public administration literature (e.g. Van Ryzin et al. 2004).

Citizen satisfaction with e-government results from a number of factors (Welch, Hinnant, and Moon 2005). Van Ryzin et al. (2004) found that overall satisfaction drives trust in local government officials and research by Vigoda-Gadot (2007) found satisfaction to be the strongest predictor of trust in governance. It has also been found that those individuals who are more satisfied with e-government and government Web sites also trust the government more, and those individuals who trust government more are also more likely to be satisfied with e-government (Welch, Hinnant, and Moon 2005). The effect of trust in e-government website on satisfaction was found to be partially mediated by system quality and service quality in the study of Teo et al. (2008), with service quality having a slightly stronger influence than system quality.

Robinson et al. (2013) found various individual factors such as political attitude to have substantive impacts on trust in administrative agencies and argue that although these are seldom measured in public administration research, their significant influence makes their inclusion in further research important. Shareef et al. (2011) found perceived ability to use to have substantial effects on both trust in e-government and adoption intentions. Grimmelikhuijsen and Meijer (2014) found that prior knowledge and disposition to trust government moderated the relationship between transparency and perceived trustworthiness. Disposition to trust is based on characteristics of the trustor (Belanger and Carter 2008) - the extent to which an individual displays an inclination to trust others and depend on them (McKnight, Choudhury, and Kacmar 2002). Therefore, disposition to trust is personality based (Mayer, Davis, and Schoorman 1995) rather than context specific and so cannot be manipulated by government agencies (Belanger and Carter 2008). Disposition to trust is especially pivotal when the situation is ambiguous and/or there is little information about the trustee's ability, benevolence, and integrity. Belanger and Carter (2008) found 
disposition to trust to significantly influence trust of the Internet and trust of the government. Lee and Rao (2009) also found disposition to trust to increase trust in e-government, whereas Beldad et al. (2012) did not find support for this.

'While e-government has the potential to improve government transparency, responsiveness, and accountability, e-services will only be adopted if citizens deem them trustworthy' (Belanger and Carter 2008, p.166). Use of e-government has been found to be related to a number of factors already highlighted. Morgeson III et al. (2011) found that e-government adoption may lead to improved citizen confidence in the future performance of that e-government agency and Welch, Hinnant, and Moon (2005) found that e-government website use is positively related to e-government satisfaction. Teo, Srivastava, and Jiang (2008) found trust in e-government website to have a direct effect on intention to continue using e-government and Tolbert and Mossberger (2006) found a significant relationship between trust and use of a local government website. On the other hand, Parent, Vandebeek, and Gemino (2005) found that e-government usage is not sufficient to induce trust in government but intensifies existing levels of trust if these are already positive.

\section{Method}

The previous section highlighted how trustworthiness of e-government services is impacted by a number of variables. However, the direct and indirect relationships between the variables describe the situation far more precisely than when they are considered in isolation. ISM is an interactive learning process: a group's adjudication decides whether and how a number of variables are related, an overall structure is extracted from the complex set of variables based on the relationships interpreted by the group, and then the specific relationships and overall structure are portrayed in a directed graph (digraph) model through a hierarchical configuration. ISM has been used by other researchers in the area to explore e-governance service delivery based on its critical success factors (Lal and Haleem 2009). ISM is a sound method for this research in order to develop insight into the collective understanding of the relationships between trustworthiness of e-government and the various variables identified in the literature review. The steps involved in the ISM technique are shown in Figure 1.

\section{Structural self-interaction matrix (steps 2, 3, 4, and 5)}

For analysing the criteria, a contextual relationship of 'helps achieve' or 'influences' is chosen. In this exercise, seven experts - three public sector professionals and four academics - whom have a mixed experience of information systems, e-government, and public administration were chosen to provide their expert views on the interrelationships of the twenty constructs selected through the review of literature (see Appendix for construct definitions and table used for the expert survey). To express the relationships between different factors of e-government trustworthiness, four symbols were used to denote the direction of a relationship between the parameters $i$ and $j$ (here $i<j$ ):

[1] $\mathbf{V}$ - construct $i$ helps achieve or influences $j$; [2] $\mathbf{A}$ - construct $j$ helps achieve or influences $i$; [3] $\mathbf{X}$ - constructs $i$ and $j$ help achieve or influence each other; [4] $\mathbf{O}$ constructs $i$ and $j$ are unrelated. 


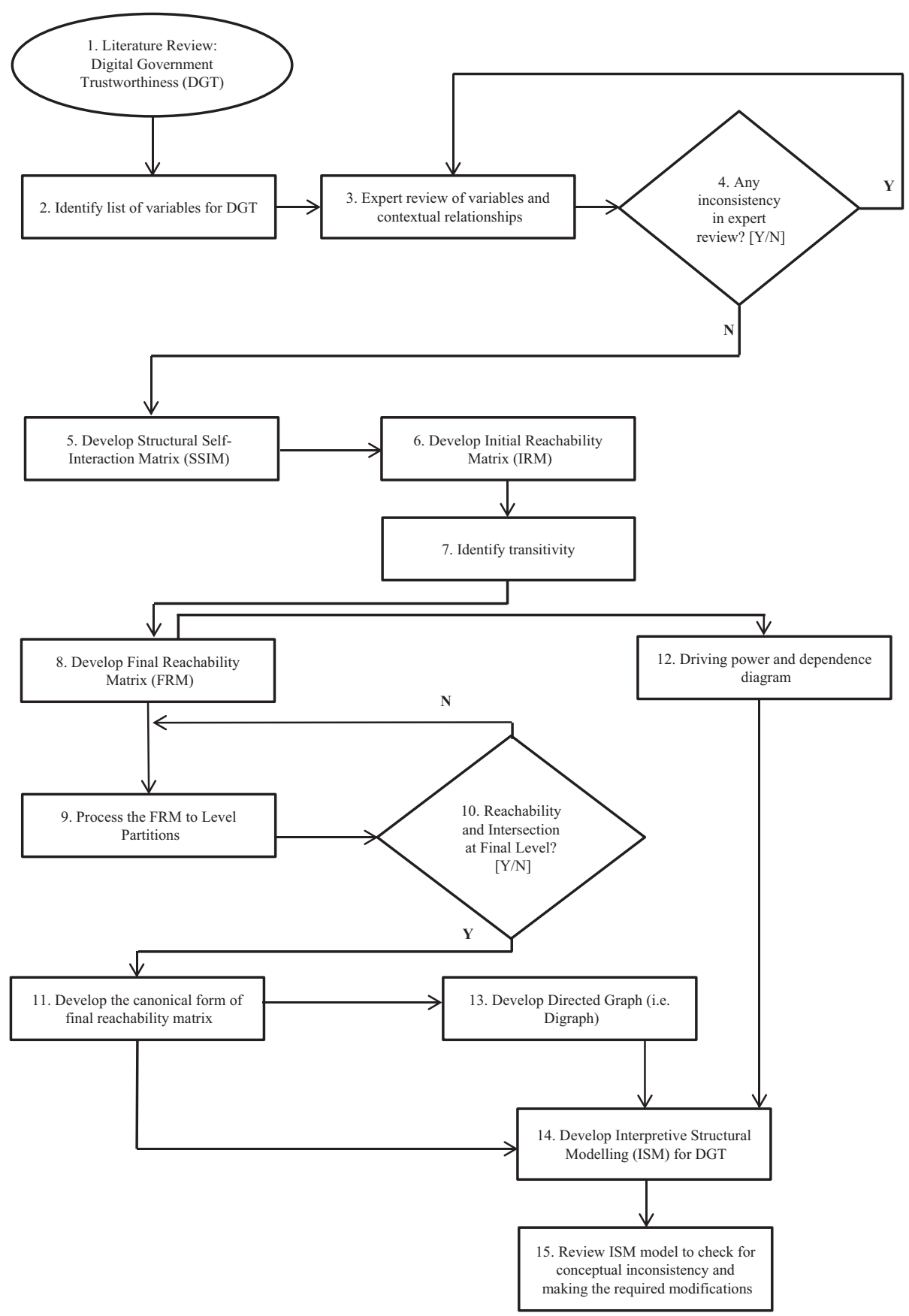

Figure 1. Flow chart for ISM method.

By collating the contextual relationships decided by each expert, the structural self-interaction matrix (SSIM) is developed (Table 1). The following statements explain the use of symbols V, A, X, O in SSIM: [1] Privacy concerns (Variable 5) 
Table 1. Structural self-interactional matrix (SSIM).

\begin{tabular}{|c|c|c|c|c|c|c|c|c|c|c|c|c|c|c|c|c|c|c|c|c|}
\hline $\operatorname{VR}[i / j]$ & 20 & 19 & 18 & 17 & 16 & 15 & 14 & 13 & 12 & 11 & 10 & 9 & 8 & 7 & 6 & 5 & 4 & 3 & 2 & 1 \\
\hline 1 & $x$ & A & A & $x$ & V & 0 & 0 & $x$ & A & A & A & A & A & A & A & A & X & $X$ & $X$ & \\
\hline 2 & $x$ & A & 0 & 0 & V & $X$ & A & $x$ & $x$ & A & $X$ & A & A & 0 & $X$ & X & X & $x$ & & \\
\hline 3 & $x$ & 0 & $x$ & 0 & V & 0 & 0 & V & A & 0 & 0 & 0 & A & 0 & A & V & V & & & \\
\hline 4 & V & A & A & 0 & V & A & A & $x$ & A & A & 0 & A & A & 0 & $x$ & $x$ & & & & \\
\hline 5 & V & 0 & A & A & V & A & A & V & A & A & A & A & A & 0 & $x$ & & & & & \\
\hline 6 & $x$ & A & A & A & V & A & A & $x$ & A & A & A & A & A & 0 & & & & & & \\
\hline 7 & V & 0 & V & V & 0 & 0 & 0 & 0 & 0 & 0 & 0 & 0 & 0 & & & & & & & \\
\hline 8 & V & 0 & $X$ & 0 & V & 0 & $X$ & V & 0 & 0 & $x$ & $X$ & & & & & & & & \\
\hline 9 & V & V & V & 0 & V & $x$ & 0 & V & V & 0 & 0 & & & & & & & & & \\
\hline 10 & V & $x$ & V & V & V & 0 & 0 & V & 0 & $x$ & & & & & & & & & & \\
\hline 11 & V & 0 & 0 & V & V & 0 & V & V & V & & & & & & & & & & & \\
\hline 12 & V & A & $x$ & V & V & V & $x$ & V & & & & & & & & & & & & \\
\hline 13 & V & A & 0 & 0 & $x$ & $x$ & A & & & & & & & & & & & & & \\
\hline 14 & V & V & V & 0 & V & V & & & & & & & & & & & & & & \\
\hline 15 & V & 0 & 0 & 0 & V & & & & & & & & & & & & & & & \\
\hline 16 & $x$ & A & A & A & & & & & & & & & & & & & & & & \\
\hline 17 & V & 0 & A & & & & & & & & & & & & & & & & & \\
\hline 18 & V & 0 & & & & & & & & & & & & & & & & & & \\
\hline 19 & V & & & & & & & & & & & & & & & & & & & \\
\hline 20 & & & & & & & & & & & & & & & & & & & & \\
\hline
\end{tabular}

1: Trust in government; 2: trust in technology; 3 : disposition to trust; 4: perceived risk; 5: privacy concerns; 6: perceived security; 7: political attitudes; 8: transparency; 9: perceived prior knowledge; 10: accountability; 11: responsiveness; 12 : service quality; 13 : satisfaction; 14: system quality; 15 : perceived ability to use; 16 : use; 17: benevolence; 18: integrity; 19: competence; 20: trustworthiness of e-government; VR[i/j]: variable $i /$ variable j.

help achieve or influence trustworthiness of e-government (Variable 20) (V); [2] system quality (Variable 14) helps achieve or influences trust in technology (Variable 2) (A); [3] satisfaction (Variable 13) and use (Variable 16) help achieve or influence each other (X); [4] transparency (Variable 8) and competence (Variable 19) are unrelated $(\mathrm{O})$.

\section{Reachability matrix (steps 6, 7, and 8)}

Next, the SSIM was converted into a binary matrix, called the initial reachability matrix, by substituting $\mathrm{V}, \mathrm{A}, \mathrm{X}$, and $\mathrm{O}$ with 1 and 0 as per the case. The substitution of $1 \mathrm{~s}$ and $0 \mathrm{~s}$ is as per the following rules: $[1]$ if the $(i, j)$ entry in the SSIM is V, the $(i$, $j$ ) entry in the reachability matrix becomes 1 and the $(j, i)$ entry becomes 0 ; [2] if the $(i, j)$ entry in the SSIM is A, the $(i, j)$ entry in the reachability matrix becomes 0 and the $(j, i)$ entry becomes $1 ;[3]$ if the $(i, j)$ entry in the SSIM is X, both the $(i, j)$ entry and $(j, i)$ entry in the reachability matrix become $1 ;[4]$ if the $(i, j)$ entry in the SSIM is $\mathrm{O}$, both the $(i, j)$ entry and $(j, i)$ entry in the reachability matrix become 0 . Following these rules, the initial reachability matrix for the trustworthiness factors of e-government is shown in Table 2.

After including transitivity, the final reachability matrix is shown in Table 3. Table 3 also shows the driving and dependence power of each variable. The driving power for each variable is the total number of variables, including itself, which it may help to achieve. On the other hand, dependence power is the total number of variables, including itself, which may help in achieving it. These driving powers and dependence powers will be used later in the classification of variables into the four groups including autonomous, dependent, linkage, and drivers. 
Table 2. Initial reachability matrix.

\begin{tabular}{lllllllllllllllllllll}
\hline VR & 1 & 2 & 3 & 4 & 5 & 6 & 7 & 8 & 9 & 10 & 11 & 12 & 13 & 14 & 15 & 16 & 17 & 18 & 19 & 20 \\
\hline 1 & 1 & 1 & 1 & 1 & 0 & 0 & 0 & 0 & 0 & 0 & 0 & 0 & 1 & 0 & 0 & 1 & 1 & 0 & 0 & 1 \\
2 & 1 & 1 & 1 & 1 & 1 & 1 & 0 & 0 & 0 & 1 & 0 & 1 & 1 & 0 & 1 & 1 & 0 & 0 & 0 & 1 \\
3 & 1 & 1 & 1 & 1 & 1 & 0 & 0 & 0 & 0 & 0 & 0 & 0 & 1 & 0 & 0 & 1 & 0 & 1 & 0 & 1 \\
4 & 1 & 1 & 0 & 1 & 1 & 1 & 0 & 0 & 0 & 0 & 0 & 0 & 1 & 0 & 0 & 1 & 0 & 0 & 0 & 1 \\
5 & 1 & 1 & 0 & 1 & 1 & 1 & 0 & 0 & 0 & 0 & 0 & 0 & 1 & 0 & 0 & 1 & 0 & 0 & 0 & 1 \\
6 & 1 & 1 & 1 & 1 & 1 & 1 & 0 & 0 & 0 & 0 & 0 & 0 & 1 & 0 & 0 & 1 & 0 & 0 & 0 & 1 \\
7 & 1 & 0 & 0 & 0 & 0 & 0 & 1 & 0 & 0 & 0 & 0 & 0 & 0 & 0 & 0 & 0 & 1 & 1 & 0 & 1 \\
8 & 1 & 1 & 1 & 1 & 1 & 1 & 0 & 1 & 1 & 1 & 0 & 0 & 1 & 1 & 0 & 1 & 0 & 1 & 0 & 1 \\
9 & 1 & 1 & 0 & 1 & 1 & 1 & 0 & 1 & 1 & 0 & 0 & 1 & 1 & 0 & 1 & 1 & 0 & 1 & 1 & 1 \\
10 & 1 & 1 & 0 & 0 & 1 & 1 & 0 & 1 & 0 & 1 & 1 & 0 & 1 & 0 & 0 & 1 & 1 & 1 & 1 & 1 \\
11 & 1 & 1 & 0 & 1 & 1 & 1 & 0 & 0 & 0 & 1 & 1 & 1 & 1 & 1 & 0 & 1 & 1 & 0 & 0 & 1 \\
12 & 1 & 1 & 1 & 1 & 1 & 1 & 0 & 0 & 0 & 0 & 0 & 1 & 1 & 1 & 1 & 1 & 1 & 1 & 0 & 1 \\
13 & 1 & 1 & 0 & 1 & 0 & 1 & 0 & 0 & 0 & 0 & 0 & 0 & 1 & 0 & 1 & 1 & 0 & 0 & 0 & 1 \\
14 & 0 & 1 & 0 & 1 & 1 & 1 & 0 & 1 & 0 & 0 & 0 & 1 & 1 & 1 & 1 & 1 & 0 & 1 & 1 & 1 \\
15 & 0 & 1 & 0 & 1 & 1 & 1 & 0 & 0 & 1 & 0 & 0 & 0 & 1 & 0 & 1 & 1 & 0 & 0 & 0 & 1 \\
16 & 0 & 0 & 0 & 0 & 0 & 0 & 0 & 0 & 0 & 0 & 0 & 0 & 1 & 0 & 0 & 1 & 0 & 0 & 0 & 1 \\
17 & 1 & 0 & 0 & 0 & 1 & 1 & 0 & 0 & 0 & 0 & 0 & 0 & 0 & 0 & 0 & 1 & 1 & 0 & 0 & 1 \\
18 & 1 & 0 & 1 & 1 & 1 & 1 & 0 & 1 & 0 & 0 & 0 & 1 & 0 & 0 & 0 & 1 & 1 & 1 & 0 & 1 \\
19 & 1 & 1 & 0 & 1 & 0 & 1 & 0 & 0 & 0 & 1 & 0 & 1 & 1 & 0 & 0 & 1 & 0 & 0 & 1 & 1 \\
20 & 1 & 1 & 1 & 0 & 0 & 1 & 0 & 0 & 0 & 0 & 0 & 0 & 0 & 0 & 0 & 1 & 0 & 0 & 0 & 1 \\
\hline
\end{tabular}

1: Trust in government; 2: trust in technology; 3: disposition to trust; 4: perceived risk; 5 : privacy concerns; 6: perceived security; 7: political attitudes; 8: transparency; 9: perceived prior knowledge; 10: accountability; 11: responsiveness; 12: service quality; 13: satisfaction; 14: system quality; 15: perceived ability to use; 16: use; 17: benevolence; 18: integrity; 19: competence; 20: trustworthiness of e-government; VR: variable.

Table 3. Final reachability matrix.

\begin{tabular}{|c|c|c|c|c|c|c|c|c|c|c|c|c|c|c|c|c|c|c|c|c|c|}
\hline VR & 1 & 2 & 3 & 4 & 5 & 6 & 7 & 8 & 9 & 10 & 11 & 12 & 13 & 14 & 15 & 16 & 17 & 18 & 19 & 20 & DRP \\
\hline 1 & 1 & 1 & 1 & 1 & $1^{*}$ & $1^{*}$ & 0 & 0 & 0 & $1^{*}$ & 0 & $1^{*}$ & 1 & 0 & $1^{*}$ & 1 & 1 & $1^{*}$ & 0 & 1 & 14 \\
\hline 2 & 1 & 1 & 1 & 1 & 1 & 1 & 0 & $1^{*}$ & $1^{*}$ & 1 & $1^{*}$ & 1 & 1 & $1^{*}$ & 1 & 1 & $1^{*}$ & $1^{*}$ & $1^{*}$ & 1 & 19 \\
\hline 3 & 1 & 1 & 1 & 1 & 1 & $1^{*}$ & 0 & $1^{*}$ & 0 & $1^{*}$ & 0 & $1^{*}$ & 1 & 0 & $1^{*}$ & 1 & $1^{*}$ & 1 & 0 & 1 & 15 \\
\hline 4 & 1 & 1 & $1^{*}$ & 1 & 1 & 1 & 0 & 0 & 0 & $1^{*}$ & 0 & $1^{*}$ & 1 & 0 & $1^{*}$ & 1 & $1^{*}$ & 0 & 0 & 1 & 13 \\
\hline 5 & 1 & 1 & $1^{*}$ & 1 & 1 & 1 & 0 & 0 & 0 & $1^{*}$ & 0 & $1^{*}$ & 1 & 0 & $1^{*}$ & 1 & $1^{*}$ & 0 & 0 & 1 & 13 \\
\hline 6 & 1 & 1 & 1 & 1 & 1 & 1 & 0 & 0 & 0 & $1^{*}$ & 0 & $1^{*}$ & 1 & 0 & $1^{*}$ & 1 & $1^{*}$ & $1^{*}$ & 0 & 1 & 14 \\
\hline 7 & 1 & $1^{*}$ & $1^{*}$ & $1^{*}$ & $1^{*}$ & $1^{*}$ & 1 & $1^{*}$ & 0 & 0 & 0 & $1^{*}$ & $1^{*}$ & 0 & 0 & $1^{*}$ & 1 & 1 & 0 & 1 & 14 \\
\hline 8 & 1 & 1 & 1 & 1 & 1 & 1 & 0 & 1 & 1 & 1 & $1^{*}$ & $1^{*}$ & 1 & 1 & $1^{*}$ & 1 & $1^{*}$ & 1 & 0 & 1 & 18 \\
\hline 9 & 1 & 1 & $1^{*}$ & 1 & 1 & 1 & 0 & 1 & 1 & $1^{*}$ & 0 & 1 & 1 & $1^{*}$ & 1 & 1 & $1^{*}$ & 1 & 1 & 1 & 18 \\
\hline 10 & 1 & 1 & $1^{*}$ & $1^{*}$ & 1 & 1 & 0 & 1 & $1^{*}$ & 1 & 1 & $1^{*}$ & 1 & $1^{*}$ & $1^{*}$ & 1 & 1 & 1 & 1 & 1 & 19 \\
\hline 11 & 1 & 1 & $1^{*}$ & 1 & 1 & 1 & 0 & $1^{*}$ & 0 & 1 & 1 & 1 & 1 & 1 & $1^{*}$ & 1 & 1 & $1^{*}$ & $1^{*}$ & 1 & 18 \\
\hline 12 & 1 & 1 & 1 & 1 & 1 & 1 & 0 & $1^{*}$ & $1^{*}$ & $1^{*}$ & 0 & 1 & 1 & 1 & 1 & 1 & 1 & 1 & $1^{*}$ & 1 & 18 \\
\hline 13 & 1 & 1 & $1^{*}$ & 1 & $1^{*}$ & 1 & 0 & 0 & $1^{*}$ & $1^{*}$ & 0 & $1^{*}$ & 1 & 0 & 1 & 1 & $1^{*}$ & 0 & 0 & 1 & 14 \\
\hline 14 & $1^{*}$ & 1 & $1^{*}$ & 1 & 1 & 1 & 0 & 1 & $1^{*}$ & $1^{*}$ & 0 & 1 & 1 & 1 & 1 & 1 & $1^{*}$ & 1 & 1 & 1 & 18 \\
\hline 15 & $1^{*}$ & 1 & $1^{*}$ & 1 & 1 & 1 & 0 & $1^{*}$ & 1 & $1^{*}$ & 0 & $1^{*}$ & 1 & 0 & 1 & 1 & 0 & $1^{*}$ & $1^{*}$ & 1 & 16 \\
\hline 16 & $1^{*}$ & $1^{*}$ & $1^{*}$ & $1^{*}$ & 0 & $1^{*}$ & 0 & 0 & 0 & 0 & 0 & 0 & 1 & 0 & $1^{*}$ & 1 & 0 & 0 & 0 & 1 & 9 \\
\hline 17 & 1 & $1^{*}$ & $1^{*}$ & $1^{*}$ & 1 & 1 & 0 & 0 & 0 & 0 & 0 & 0 & $1^{*}$ & 0 & 0 & 1 & 1 & 0 & 0 & 1 & 10 \\
\hline 18 & 1 & $1^{*}$ & 1 & 1 & 1 & 1 & 0 & 1 & $1^{*}$ & $1^{*}$ & 0 & 1 & $1^{*}$ & $1^{*}$ & $1^{*}$ & 1 & 1 & 1 & 0 & 1 & 17 \\
\hline 19 & 1 & 1 & $1^{*}$ & 1 & $1^{*}$ & 1 & 0 & $1^{*}$ & 0 & 1 & $1^{*}$ & 1 & 1 & $1^{*}$ & $1^{*}$ & 1 & $1^{*}$ & $1^{*}$ & 1 & 1 & 18 \\
\hline 20 & 1 & 1 & 1 & $1^{*}$ & $1^{*}$ & 1 & 0 & 0 & 0 & $1^{*}$ & 0 & $1^{*}$ & $1^{*}$ & 0 & $1^{*}$ & 1 & $1^{*}$ & $1^{*}$ & 0 & 1 & 14 \\
\hline DNP & 20 & 20 & 20 & 20 & 19 & 20 & 1 & 12 & 9 & 17 & 5 & 18 & 20 & 9 & 18 & 20 & 18 & 15 & 8 & 20 & 309 \\
\hline
\end{tabular}

$1^{*}$ : Shows transitivity; 1 : trust in government; 2 : trust in technology; 3 : disposition to trust; 4: perceived risk; 5: privacy concerns; 6: perceived security; 7: political attitudes; 8: transparency; 9: perceived prior knowledge; 10: accountability; 11: responsiveness; 12: service quality; 13: satisfaction; 14: system quality; 15: perceived ability to use; 16: use; 17: benevolence; 18: integrity; 19: competence; 20: trustworthiness of e-government; DNP: dependence power; DRP: driving power; VR: variable. 


\section{Level partitions (steps 9 and 10)}

The matrix is partitioned by assessing the reachability and antecedent sets for each variable (Warfield 1974). The final reachability matrix leads to the reachability and antecedent set for each factor relating to trustworthiness of e-government. The reachability set $R\left(s_{i}\right)$ of the variable $s_{i}$ is the set of variables defined in the columns that contained 1 in row $s_{i}$. Similarly, the antecedent set $A\left(s_{i}\right)$ of the variable $s_{i}$ is the set of variables defined in the rows, which contain 1 in the column $s_{i}$. Then, the interaction of these sets is derived for all the variables. The variables for which the intersection of reachability and intersection sets results into reachability sets (i.e. $R\left(s_{i}\right) \cap A\left(s_{i}\right)=R\left(s_{i}\right)$ ) are the top-level variables of the ISM hierarchy. The top-level variables of the hierarchy would not help to achieve any other variable above their own level in the hierarchy.

Once the top-level variables are identified, they are separated out from the rest of the variables. Then, the same process is repeated to find out the next level of variables, and so on. These identified levels help in building the diagraph and the final ISM model (Agarwal, Shankar, and Tiwari 2007; Dwivedi et al., 2016b; Hughes et al. 2016; Singh, Garg, and Deshmukh 2007). In the present context, the variables along with their reachability set, antecedent set, and the top level are shown in Table 4. The process is completed in five iterations (Tables 4-8) documented below. In Table 4 , nine variables namely 1 (trust in government), 2 (trust in technology), 3 (disposition to trust), 4 (perceived risk), 6 (perceived security), 13 (satisfaction), 15 (perceived ability to use), 16 (use), and 20 (trustworthiness of e-government) are found at level I, as the elements for these variables at reachability and intersection set are the same. So, they will be positioned at the top of the hierarchy (i.e. level I) of the ISM model. As a result, the rows corresponding to variables $1,2,3,4,6,13,15,16$, and 20 are removed from further inclusion (see Table 5). The same process of deleting the rows corresponding to the previous level and marking the next level position to the new table is repeated until the final variable in the table is reached.

In Table 5, the variables 5 (privacy concerns) and 17 (benevolence) are put at level II, as the elements (i.e. elements $5,10,12$, and 17 for variable 5 and elements 5 and 17 for variable 17) for these variables at reachability and intersection set are the same. Thus, they will be positioned at level II in the ISM model.

In Table 6, variables 8 (transparency), 10 (accountability), 12 (service quality), 14 (system quality), and 18 (integrity) are put at level III as, the elements (i.e. 8, 10, 12, 14 , and 18) at reachability set and intersection set for these variables are the same. Thus, they will be positioned at level III in the ISM model.

In Table 7, variables 7 (political attitude), 11 (responsiveness), and 19 (competence) are put at level IV as the elements at reachability set and intersection set for these variables are the same. Thus, they will be positioned at level IV in the ISM model.

In Table 8, variable 9 (perceived prior knowledge) is put at level $\mathrm{V}$, as the element (i.e. 9) at reachability set and intersection set for this variable is the same. Thus, it will be positioned at level $\mathrm{V}$ in the ISM model.

\section{Developing canonical matrix (step 11)}

A canonical matrix is developed by clustering variables in the same level, across the rows and columns of the final reachability matrix as shown in Table 9. This matrix is 


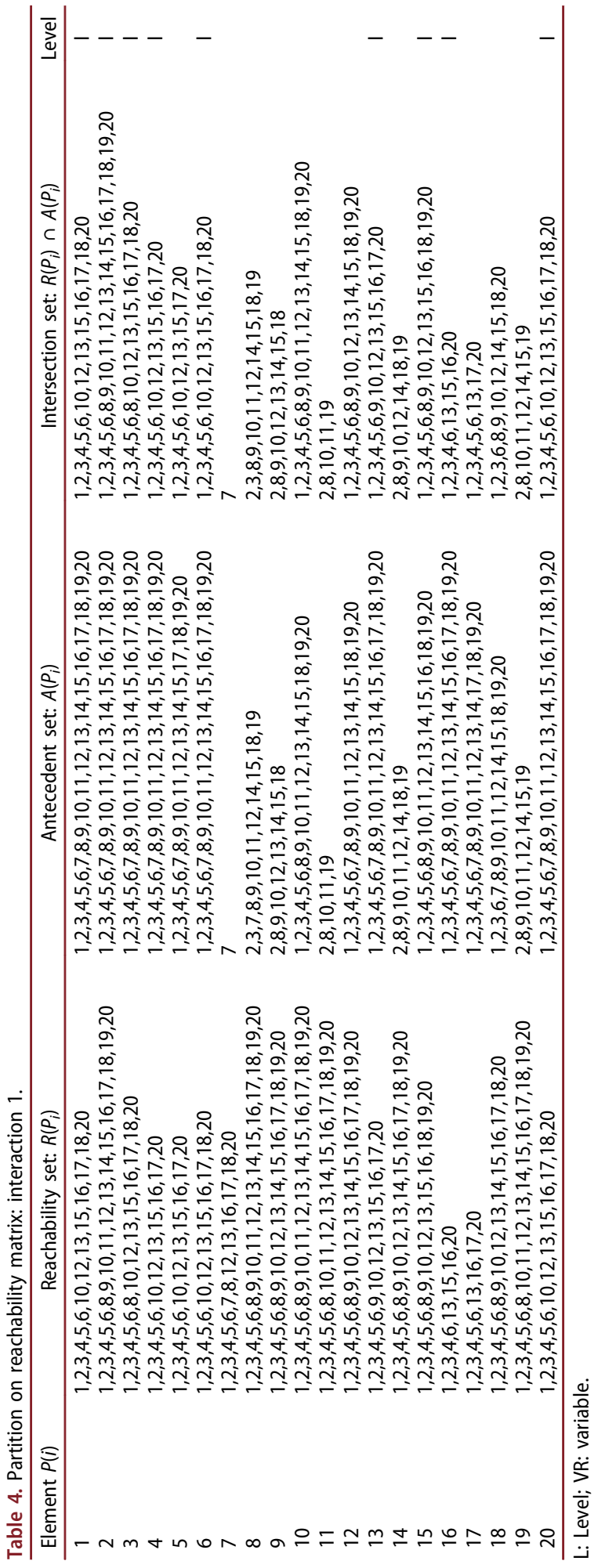


Table 5. Partition on reachability matrix: interaction 2.

\begin{tabular}{llllc}
\hline Element $P(i)$ & \multicolumn{1}{c}{ Reachability set: $R\left(P_{i}\right)$} & \multicolumn{1}{c}{ Antecedent set: $A\left(P_{i}\right)$} & Intersection set: $R\left(P_{i}\right) \cap A\left(P_{i}\right)$ & Level \\
\hline 5 & $5,10,12,17$ & $5,7,8,9,10,11,12,14,17,18,19$ & $5,10,12,17$ & II \\
7 & $5,7,8,12,17,18$ & 7 & 7 & \\
8 & $5,8,9,10,11,12,14,17,18,19$ & $7,8,9,10,11,12,14,18,19$ & $8,9,10,11,12,14,18,19$ & \\
9 & $5,8,9,10,12,14,17,18,19$ & $8,9,10,12,14,18$ & $8,9,10,12,14,18$ & \\
10 & $5,8,9,10,11,12,14,17,18,19$ & $5,8,9,10,11,12,14,18,19$ & $5,8,9,10,11,12,14,18,19$ & \\
11 & $5,8,10,11,12,14,17,18,19$ & $8,10,11,19$ & $8,10,11,19$ & \\
12 & $5,8,9,10,12,14,17,18,19$ & $5,7,8,9,10,11,12,14,18,19$ & $5,8,9,10,12,14,18,19$ & \\
14 & $5,8,9,10,12,14,17,18,19$ & $8,9,10,11,12,14,18,19$ & $8,9,10,12,14,18,19$ & \\
17 & 5,17 & $5,7,8,9,10,11,12,14,17,18,19$ & 5,17 \\
18 & $5,8,9,10,12,14,17,18$ & $7,8,9,10,11,12,14,18,19$ & $8,9,10,12,14,18$ & \\
19 & $5,8,10,11,12,14,17,18,19$ & $8,9,10,11,12,14,19$ & $8,10,11,12,14,19$ & \\
\hline
\end{tabular}

Table 6. Partition on reachability matrix: interaction 3.

\begin{tabular}{lllll}
\hline Element $P(i)$ & Reachability set: $R\left(P_{i}\right)$ & Antecedent set: $A\left(P_{i}\right)$ & Intersection set: $R\left(P_{i}\right) \cap A\left(P_{i}\right)$ & Level \\
\hline 7 & $7,8,12,18$ & 7 & 7 & \\
8 & $8,9,10,11,12,14,18,19$ & $7,8,9,10,11,12,14,18,19$ & $8,9,10,11,12,14,18,19$ & III \\
9 & $8,9,10,12,14,18,19$ & $8,9,10,12,14,18$ & $8,9,10,12,14,18$ & \\
10 & $8,9,10,11,12,14,18,19$ & $8,9,10,11,12,14,18,19$ & $8,9,10,11,12,14,18,19$ & III \\
11 & $8,10,11,12,14,18,19$ & $8,10,11,19$ & $8,10,11,19$ & \\
12 & $8,9,10,12,14,18,19$ & $7,8,9,10,11,12,14,18,19$ & $8,9,10,12,14,18,19$ & III \\
14 & $8,9,10,12,14,18,19$ & $8,9,10,11,12,14,18,19$ & $8,9,10,12,14,18,19$ & III \\
18 & $8,9,10,12,14,18$ & $7,8,9,10,11,12,14,18,19$ & $8,9,10,12,14,18$ & III \\
19 & $8,10,11,12,14,18,19$ & $8,9,10,11,12,14,19$ & $8,10,11,12,14,19$ & \\
\hline
\end{tabular}

Table 7. Partition on reachability matrix: interaction 4.

\begin{tabular}{lcccc}
\hline Element $P(i)$ & Reachability set: $R\left(P_{i}\right)$ & Antecedent set: $A\left(P_{i}\right)$ & Intersection set: $R\left(P_{i}\right) \cap A\left(P_{i}\right)$ & Level \\
\hline 7 & 7 & 7 & 7 & IV \\
9 & 9,19 & 9 & 9 & IV \\
11 & 11,19 & 11,19 & 11,19 & 11,19 \\
19 & 11,19 & $9,11,19$ & IV \\
\hline
\end{tabular}

Table 8. Partition on reachability matrix: interaction 5.

\begin{tabular}{lcccc}
\hline Element $P(i)$ & Reachability set: $R\left(P_{i}\right)$ & Antecedent set: $A\left(P_{i}\right)$ & Intersection set: $R\left(P_{i}\right) \cap A\left(P_{i}\right)$ & Level \\
\hline 9 & 9 & 9 & 9 & V \\
\hline
\end{tabular}

another more convenient form of the final reachability matrix (i.e. Table 3 ) as far as drawing the ISM model is concerned. This matrix helps in the generation of the digraph and later on structural model.

\section{Classification of e-government trustworthiness factors (step 12)}

The trustworthiness factors are classified into four categories based on driving power and dependence power. They include autonomous, dependent, linkage, and drivers (Mandal and Deshmukh 1994). The driving power and dependence power of each of these trustworthiness factors are shown in Table 3. Thereafter, the driver powerdependence power diagram is shown in Figure 2. 
Table 9. Canonical form of final reachability matrix.

\begin{tabular}{lrrrrrrrrrrrrrrrrrrrrrr}
\hline VR & 1 & 2 & 3 & 4 & 6 & 13 & 15 & 16 & 20 & 5 & 17 & 8 & 10 & 12 & 14 & 18 & 7 & 11 & 19 & 9 & LVL \\
\hline 1 & 1 & 1 & 1 & 1 & 1 & 1 & 1 & 1 & 1 & 1 & 1 & 0 & 1 & 1 & 0 & 1 & 0 & 0 & 0 & 0 & I \\
2 & 1 & 1 & 1 & 1 & 1 & 1 & 1 & 1 & 1 & 1 & 1 & 1 & 1 & 1 & 1 & 1 & 0 & 1 & 1 & 1 & I \\
3 & 1 & 1 & 1 & 1 & 1 & 1 & 1 & 1 & 1 & 1 & 1 & 1 & 1 & 1 & 0 & 1 & 0 & 0 & 0 & 0 & I \\
4 & 1 & 1 & 1 & 1 & 1 & 1 & 1 & 1 & 1 & 1 & 1 & 0 & 1 & 1 & 0 & 0 & 0 & 0 & 0 & 0 & I \\
6 & 1 & 1 & 1 & 1 & 1 & 1 & 1 & 1 & 1 & 1 & 1 & 0 & 1 & 1 & 0 & 1 & 0 & 0 & 0 & 0 & I \\
13 & 1 & 1 & 1 & 1 & 1 & 1 & 1 & 1 & 1 & 1 & 1 & 0 & 1 & 1 & 0 & 0 & 0 & 0 & 0 & 1 & I \\
15 & 1 & 1 & 1 & 1 & 1 & 1 & 1 & 1 & 1 & 1 & 0 & 1 & 1 & 1 & 0 & 1 & 0 & 0 & 1 & 1 & I \\
16 & 1 & 1 & 1 & 1 & 1 & 1 & 1 & 1 & 1 & 0 & 0 & 0 & 0 & 0 & 0 & 0 & 0 & 0 & 0 & 0 & I \\
20 & 1 & 1 & 1 & 1 & 1 & 1 & 1 & 1 & 1 & 1 & 1 & 0 & 1 & 1 & 0 & 1 & 0 & 0 & 0 & 0 & I \\
5 & 1 & 1 & 1 & 1 & 1 & 1 & 1 & 1 & 1 & 1 & 1 & 0 & 1 & 1 & 0 & 0 & 0 & 0 & 0 & 0 & II \\
17 & 1 & 1 & 1 & 1 & 1 & 1 & 0 & 1 & 1 & 1 & 1 & 0 & 0 & 0 & 0 & 0 & 0 & 0 & 0 & 0 & II \\
8 & 1 & 1 & 1 & 1 & 1 & 1 & 1 & 1 & 1 & 1 & 1 & 1 & 1 & 1 & 1 & 1 & 0 & 1 & 1 & 1 & III \\
10 & 1 & 1 & 1 & 1 & 1 & 1 & 1 & 1 & 1 & 1 & 1 & 1 & 1 & 1 & 1 & 1 & 0 & 1 & 1 & 1 & III \\
12 & 1 & 1 & 1 & 1 & 1 & 1 & 1 & 1 & 1 & 1 & 1 & 1 & 1 & 1 & 1 & 1 & 0 & 0 & 1 & 1 & III \\
14 & 1 & 1 & 1 & 1 & 1 & 1 & 1 & 1 & 1 & 1 & 1 & 1 & 1 & 1 & 1 & 1 & 0 & 0 & 1 & 1 & III \\
18 & 1 & 1 & 1 & 1 & 1 & 1 & 1 & 1 & 1 & 1 & 1 & 1 & 1 & 1 & 1 & 1 & 0 & 0 & 0 & 1 & III \\
7 & 1 & 1 & 1 & 1 & 1 & 1 & 0 & 1 & 1 & 1 & 1 & 1 & 0 & 1 & 0 & 1 & 1 & 0 & 0 & 0 & IV \\
11 & 1 & 1 & 1 & 1 & 1 & 1 & 1 & 1 & 1 & 1 & 1 & 1 & 1 & 1 & 1 & 1 & 0 & 1 & 1 & 0 & IV \\
19 & 1 & 1 & 1 & 1 & 1 & 1 & 1 & 1 & 1 & 1 & 1 & 1 & 1 & 1 & 1 & 1 & 0 & 1 & 1 & 0 & IV \\
9 & 1 & 1 & 1 & 1 & 1 & 1 & 1 & 1 & 1 & 1 & 1 & 1 & 1 & 1 & 1 & 1 & 0 & 0 & 1 & 1 & V \\
LVL & I & I & I & I & I & I & I & I & I & II & II & III & III & III & III & III & IV & IV & IV & V & \\
\hline
\end{tabular}

1: Trust in government; 2: trust in technology; 3: disposition to trust; 4: perceived risk; 5: privacy concerns; 6: perceived security; 7: political attitudes; 8: transparency; 9: perceived prior knowledge; 10: accountability; 11: responsiveness; 12 : service quality; 13 : satisfaction; 14 : system quality; 15 : perceived ability to use; 16: use; 17: benevolence; 18: integrity; 19: competence; 20: trustworthiness of e-government; DNP: dependence power; DRP: driving power; VR: variable.

This figure has four quadrants that represent the autonomous, dependent, linkage, and drivers sections. For example, a factor (i.e. 16) that has a driving power of 9 and dependence power of 20 is positioned at a place with dependence power of 20 in the $X$-axis and driving power of 9 on the $Y$-axis. Based on its position, it can be defined as a strong dependent variable. Similarly, a factor (i.e. 11) having a driving power of 18 and a dependence power of 5 can be positioned at dependence power of 5 at the $X$-axis and driving power of 18 on the $Y$-axis. Based on its position, it can be defined as a driving variable.

The objective behind the classification is to analyse the driver power and dependency of the trustworthiness factors. The first cluster includes autonomous trustworthiness factors that have weak driver power and weak dependence. These factors are relatively disconnected from the system. In the context of the current research, no factors belong to this cluster. The second cluster consists of the dependent variables that have weak driver power but strong dependence. Use (variable 16) and benevolence (variable 17) belong to this cluster.

The third cluster has the linkage variables that have strong driver power and strong dependence. Any action on these variables will have an effect on the others and also a feedback effect on themselves (Talib, Rahman, and Qureshi 2011a). Most of the variables including 1 (trust in government), 2 (trust in technology), 3 (disposition to trust), 4 (perceived risk), 5 (privacy concerns), 6 (perceived security), 8 (transparency), 10 (accountability), 12 (service quality), 13 (satisfaction), 15 (perceived ability to use), 18 (integrity), and 20 (trustworthiness of e-government) belong to this cluster. Though the lower level variables induce or influence these variables, these also have significant driving power to influence some other variables, which are 


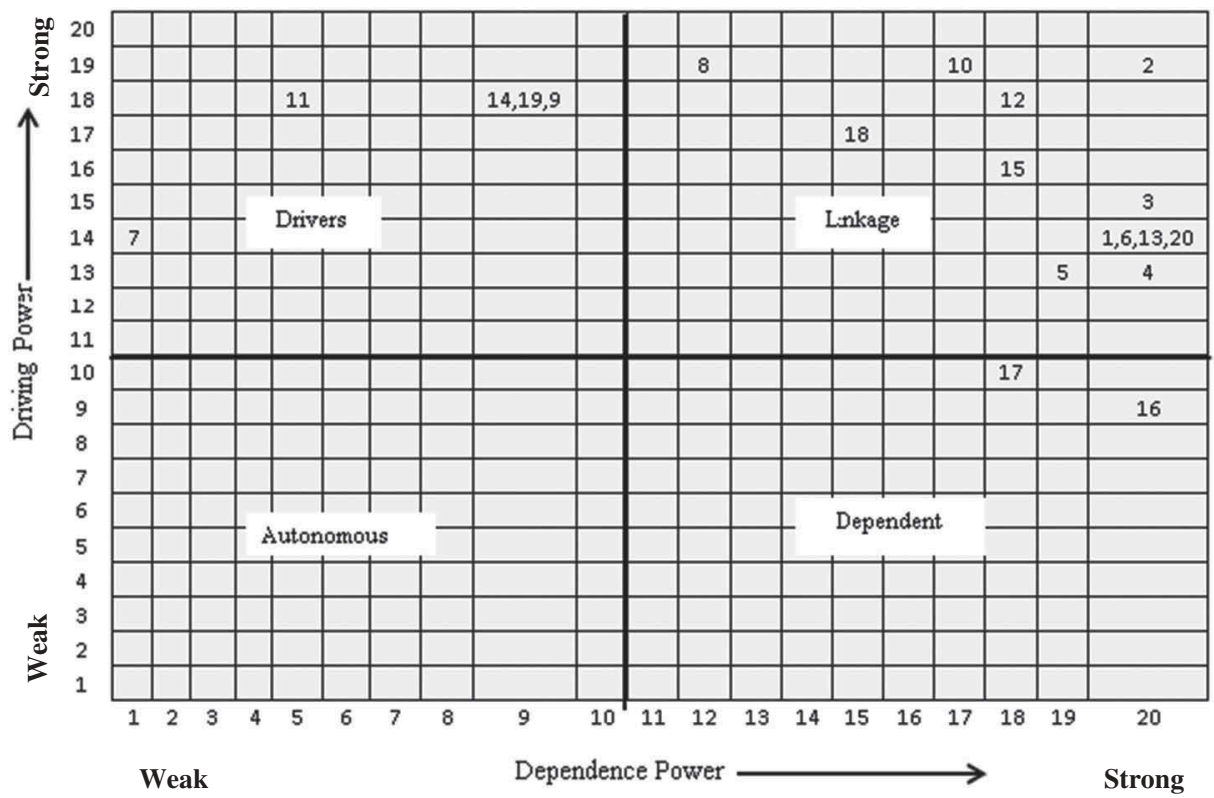

Figure 2. Driving power and dependence diagram.

at the top of the model. In fact, most of the variables on the top level of the ISM model (see Figure 3) are linkage variables interrelated to each other, which clearly indicate that they have strong driving powers to influence other linkage variables at the same top level. The fourth cluster includes drivers or independent variables with strong driving power and weak dependence. The variables including 7 (political attitude), 9 (perceived prior knowledge), 11 (responsiveness), 14 (system quality), and 19 (competence) belong to this cluster.

\section{Formation of ISM (steps 13, 14, and 15)}

From the canonical form of the reachability matrix (see Table 9), the structural model is generated by means of vertices and nodes and lines of edges. If there is a relationship between the e-government trustworthiness factors $i$ and $j$, this is shown by an arrow that points from $i$ to $j$. This graph is called directed graph or digraph. After removing the indirect links as presented in the ISM method, the digraph is finally converted into an ISM-based model as shown in Figure 3.

From Figure 3, it is observed that perceived prior knowledge (variable 9) plays a significant driving role in improving e-government trustworthiness and so it comes at the base of the ISM hierarchy (i.e. level V). The variables such as trust in government (variable 1), trust in technology (variable 2), disposition to trust (variable 3 ), perceived risk (variable 4), perceived security (variable 6), satisfaction (variable 13), perceived ability to use (variable 15), use (variable 16), and trustworthiness of e-government (variable 20) depend on the other variables for improving them for the 


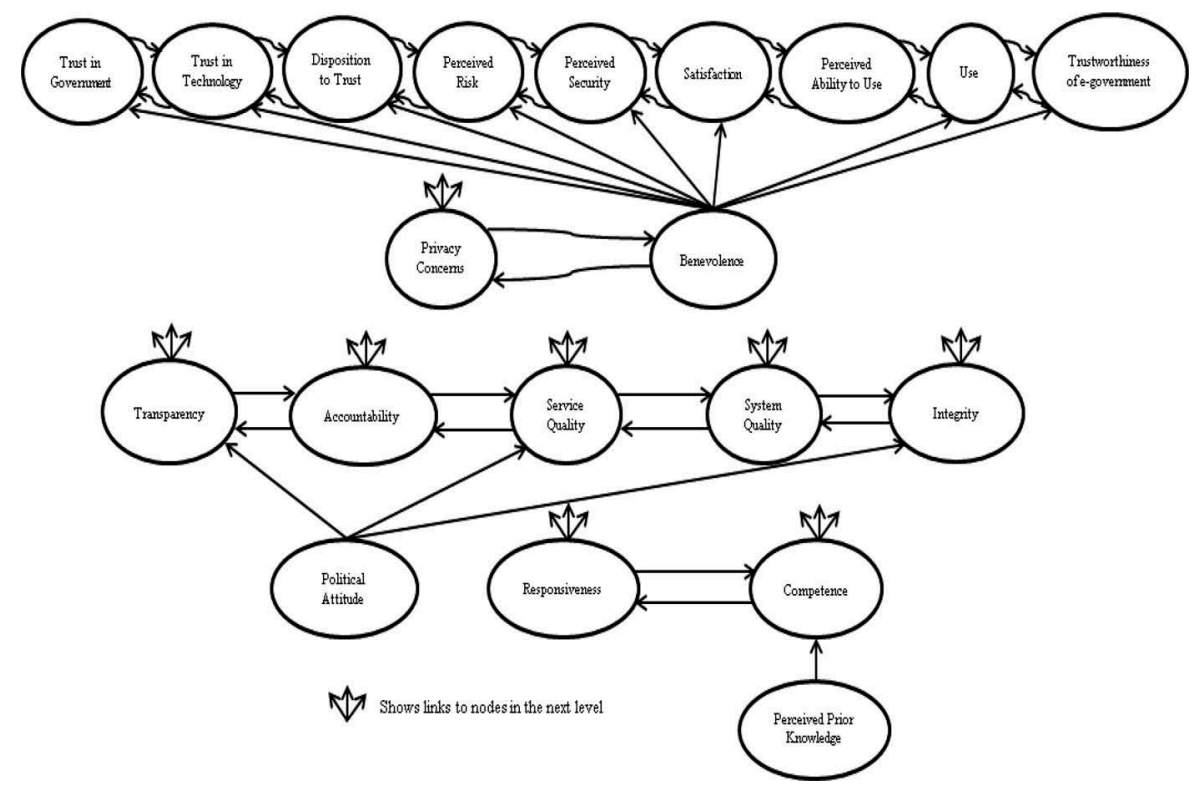

Figure 3. ISM-based model for examining e-government trustworthiness.

effective implementation of the e-government services. These variables have appeared at the top of the hierarchy (i.e. level I).

Perceived prior knowledge (variable 9), political attitude (variable 7), responsiveness (variable 11), and competence (variable 19) provide the basis for successful e-government services. The level of convenience or the degree of immediate feedback provided by the government (i.e. responsiveness), as well as the degree to which e-government possesses the skills needed to enable it to perform tasks in serving the public (i.e. competence), leads to improved transparency, accountability, service quality, system quality, and integrity of the e-government system providing services to citizens. Prior studies on e-government have shown responsiveness as the core attribute to improve service quality (e.g. Tan, Benbasat, and Cenfetelli 2008; Tolbert and Mossberger 2006).

Transparency (variable 8 ), accountability (variable 10), service quality (variable 12), system quality (variable 14), and integrity (variable 18) will influence privacy concerns and benevolence (i.e. degree to which citizens believe that e-government cares about them and wants to help them). The strong relationship of service quality with benevolence at the next upper level is also supported by prior research (e.g. Tan, Benbasat, and Cenfetelli 2008).

Privacy concerns (variable 5) and benevolence (variable 17) impact trust in government (variable 1), trust in technology (variable 2), disposition to trust (variable 3), perceived risk (variable 4), perceived security (variable 6), satisfaction (variable 13), perceived ability to use (variable 15), use (variable 16), and trustworthiness of e-government (variable 20) at the next, and final, level of the ISM model. Privacy concerns may play an even more important role when individuals' personal information is used for exploring and availing certain transactional e-government services. This is the reason why such services are more directly 
linked to individual's trust, risk, and satisfaction aspects. This also implies that privacy concerns are prerequisites to predisposition to trust, trust, risk, security, satisfaction, perceived ability to use, use, and lastly to trustworthiness of e-government.

The strong interrelationships between trust and satisfaction in the ISM model are also supported by Welch, Hinnant, and Moon (2005) who argued that higher levels of individuals' trust in government leads to their satisfaction with e-government services and web sites, and that the more satisfied individuals are with e-government or government web sites leads to greater trust in the government. The relationships between trust and risk, risk and security, security and satisfaction, and use and trustworthiness have also been highlighted by the previous literature on e-government (e.g. Belanger and Carter 2008; Chan et al. 2010; Karavasilis, Zafiropoulos, and Vrana 2010; Schaupp and Carter 2010).

\section{Findings and discussion}

Trustworthiness of e-government plays a vital role as far as citizens' use of e-government services is concerned. To be able to effectively design and implement the framework for e-government trustworthiness, we need to know the factors that significantly influence it, whether directly or indirectly. Using ISM, the interrelationships between the wide-variety of variables associated with e-government trustworthiness identified in the literature review were revealed to provide a comprehensive conceptualization that was lacking in the existing research. The major findings of this study are as follows:

(1) Autonomous variables generally appear as weak drivers and weak dependents and are relatively disconnected from the system. These variables do not have much influence on the other variables of the system (Singh, Garg, and Deshmukh 2007). The driving power-dependence power diagram indicates that there are no autonomous variables.

(2) Use (variable 16) and benevolence (variable 17) are weak drivers but strong dependent variables. They are situated further up the ISM hierarchy (see Figure 3). These variables represent the desired objectives for any successful e-government implementation and adoption and are classified largely as dependent variables. Hence, practitioners, policy makers, and managers should take special care to handle these (Talib, Rahman, and Qureshi 2011b).

(3) The largest number of variables falls in the quadrant of linkage variables in context of the current driving power-dependence power diagram. These variables include trust in government (variable 1), trust in technology (variable 2), disposition to trust (variable 3), perceived risk (variable 4), perceived security (variable 6), transparency (variable 8), accountability (variable 10), service quality (variable 12), satisfaction (variable 13), perceived ability to use (variable 15), integrity (variable 18), and trustworthiness of e-government (variable 20). This quadrant is primarily known for strong driving power and strong dependence power. Therefore, it can be inferred that among all twenty variables chosen in this research, 13 variables identified for e-government trustworthiness are unstable (see Singh, Garg, and Deshmukh 2007; Talib, Rahman, and Qureshi 2011b). 
(4) The variables in the driving power-dependence power diagram including political attitude (variable 7), perceived prior knowledge (variable 9), responsiveness (variable 11), and competence (variable 19) are almost at the bottom of the ISM model with strong driving power. These variables will help the e-government implementation agencies to achieve their desired objectives and are classified as independent variables or drivers (Agarwal, Shankar, and Tiwari 2007). Therefore, these variables need consistent attention from management focussed on improving e-government trustworthiness.

(5) The ISM-based model (see Figure 3) indicates that the variables trust in government, trust in technology, disposition to trust, perceived risk, perceived security, satisfaction, perceived ability to use, use and trustworthiness of e-government are at the top of the model and hence indicate the most significant set of dependent variables of the developed framework. Similarly, perceived prior knowledge falls as the bottom-most variable of the ISM model with one of the highest driving powers. This indicates that perceived prior knowledge would drive other variables to achieve the desired objectives.

The findings of this study provide both theoretical and practical contributions. Considering theoretical contributions, the study has integrated the literature related to trustworthiness from both public management and e-government domains. Very few previous studies have examined factors contributing to trustworthiness of public services and those that have (e.g. Yang and Anguelov 2013) did not consider a wide range of associated variables nor did they focus on citizen's trustworthiness of e-government services. Therefore, this is the first study to provide a comprehensive framework of e-government in the citizen context. Additionally, this is the first study to utilize the ISM method in this area, thus also offering a methodological contribution.

eflecting on practical contributions, the proposed ISM-based model for identification and ranking of factors influencing e-government trustworthiness provides decision makers and practitioners a more realistic representation of the problem in the course of implementing e-government. The utility of the proposed ISM method lies in imposing order and direction on the complexity of relationships among these factors, which would help decision makers and practitioners of e-government to better utilize their available resources for maximizing the trustworthiness of their e-government services. The framework allows government policy makers to effectively incorporate these factors at the implementation (i.e. supply-side perspective of e-government services) and adoption (i.e. demand-side perspective of e-government services) phases, which can help avoid failure of emerging digital government projects (Dwivedi et al. 2015).

The findings of this study can serve as an eye opener for those government organizations that implement e-government services and lack prior perceived knowledge about e-government to its stakeholders, responsiveness demonstrated by its providers, its competence and service and system quality as some of those prominent factors, which are found to be the basic factors of e-government trustworthiness. ISM also helps in classifying variables into autonomous, dependent, linkage, and driver categories. Management may use their resources towards the identified factors among these categories to accomplish the optimization of resources. Moreover, the systematic framework proposed in this research has a widespread application and can be used 
to improve government's effectiveness, performance, and managing abilities towards generating citizens' trust in e-government services.

\section{Conclusion}

Most research that considers the impact of e-government on citizens' trust in government remain at the macro-level and miss out on the deeper understanding of the interaction between the factors that directly or indirectly influence trustworthiness of e-government. The key objective of the present study was to identify and develop a hierarchy of factors influencing trustworthiness of e-government services in the citizen context. Based on a comprehensive literature review, nineteen factors were found to be associated with trustworthiness of e-government, identified as benevolence, integrity, trust in government, trust in technology, transparency, responsiveness, competence, accountability, privacy concerns, perceived security, perceived risk, system quality, service quality, satisfaction, political attitude, perceived ability to use, perceived prior knowledge, disposition to trust, and use. The review highlighted that the relationships between these factors was ill-understood and there was no single work addressing all these factors. Furthermore, there was a lack of model testing and framework development in the area of public administration research. Utilizing ISM, the interrelationships between the twenty constructs were analysed. The findings indicated that trustworthiness of e-government and its use were considered as the ultimate dependent variables, clearly implying that higher levels of trustworthiness can lead to improved use and vice-versa. The driving power and dependence diagram also indicate that the factors such as political attitude (variable 7), perceived prior knowledge (variable 9), responsiveness (variable 11), system quality (variable 14), and competence (variable 19) are factors with relatively weak dependence but strong driving power whereas factors such as use (variable 16) and benevolence (variable 17) are factors with relatively weak driving but strong dependence power. All other factors were found to demonstrate strong driving as well as dependence power. These findings can be helpful for managers, practitioners, and policy makers in framing their further strategies for effectively and successfully implementing e-government services for citizens.

The most prominent contribution of this research lies in the development of contextual relationships among various identified factors influencing e-government trustworthiness through a single multi-level framework. However, like any other research, this study is not without limitations. First, the present model has not been statistically tested and validated. It is likely that relationships are context dependent. Second, this paper is limited only to implication of ISM methodology in modelling the practices of trustworthiness in e-government. Future research should extend this work with empirical validation of the proposed framework across different e-government services in various other contexts.

\section{Disclosure statement}

No potential conflict of interest was reported by the authors. 


\section{Notes on contributors}

Marijn Janssen is full professor in ICT \& Governance and head of the Information and Communication Technology section of the Technology, Policy and Management Faculty of Delft University of Technology. He is co-editor-in-chief of Government Information Quarterly (GIQ) and is conference chair of IFIP EGOV conference series. More information: www.tbm.tudelft.nl/marijnj.

Nripendra P. Rana is an associate professor in the School of Management at Swansea University, UK. With an academic and professional background in Mathematics and Computer Science and with $\mathrm{PhD}$ in Information Systems, his current research interests focus primarily upon adoption of emerging and cutting edge technology in general and e-government, m-government, e-commerce, and $\mathrm{m}$-commerce systems in particular.

Emma L. Slade is Deputy Director of Postgraduate Research in the School of Management at Swansea University, UK. Her research interests revolve around technology adoption, social media, consumer behaviour, and environmentalism. Full list of publications can be found on Google Scholar. In 2016, Emma was selected for participation in the Digital Economy Crucible, funded by EPSRC as part of CHERISH-DE.

Yogesh K. Dwivedi is a professor of Digital and Social Media and Director of Research in the School of Management at Swansea University, UK. His research interests are in the area of Information Systems (IS) including the adoption and diffusion of emerging ICTs, electronic government and digital and social media marketing. More information: http://www.swansea.ac.uk/staff/som/aca demic-staff/y.k.dwivedi/.

\section{ORCID}

Marijn Janssen (D) http://orcid.org/0000-0001-6211-8790

\section{References}

Agarwal, A., R. Shankar, and M. K. Tiwari. 2007. "Modeling Agility of Supply Chain.” Industrial Marketing Management 36 (4): 443-457. doi:10.1016/j.indmarman.2005.12.004.

Asgarkhani, M. 2005. "Digital Government and Its Effectiveness in Public Management Reform: A Local Government Perspective." Public Management Review 7 (3): 465-487. doi:10.1080/ 14719030500181227.

Baldwin, J. N., R. Gauld, and S. Goldfinch. 2012. "What Public Servants Really Think of E-Government." Public Management Review 14 (1): 105-127. doi:10.1080/14719037.2011.589616.

Behn, R. 1995. "The Big Questions of Public Management." Public Administration Review 55 (4): 313-324. doi:10.2307/977122.

Belanger, F., and L. Carter. 2008. "Trust and Risk in E-Government Adoption.” Journal of Strategic Information Systems 17 (2): 165-176. doi:10.1016/j.jsis.2007.12.002.

Belanger, F., J. Hiller, and W. Smith. 2002. "Trustworthiness in Electronic Commerce: The Role of Privacy, Security, and Site Attributes." Journal of Strategic Information Systems 11 (3-4): 245-270. doi:10.1016/S0963-8687(02)00018-5.

Beldad, A., T. van der Geest, M. De Jong, and M. Steehouder. 2012. “A Cue or Two and I'll Trust You: Determinants of Trust in Government Organizations in Terms of Their Processing and Usage of Citizens' Personal Information Disclosed Online." Government Information Quarterly 29 (1): 41-49. doi:10.1016/j.giq.2011.05.003.

Bellamy, C., and J. A. Taylor. 1998. Governing in the Information Age. Buckingham: Open University Press.

Campbell, J. W., and T. Im. 2015. "Identification and Trust in Public Organizations: A Communicative Approach." Public Management Review 17 (8): 1065-1084. doi:10.1080/ 14719037.2014.881531. 
Carter, L., and F. Belanger. 2005. "The Utilization of E-Government Services: Citizen Trust, Innovation and Acceptance Factors." Information Systems Journal 15 (1): 5-25. doi:10.1111/ j.1365-2575.2005.00183.x.

Chan, F. K., J. Y. Thong, V. Venkatesh, S. A. Brown, P. J. Hu, and K. Y. Tam. 2010. "Modeling Citizen Satisfaction with Mandatory Adoption of an E-Government Technology." Journal of the Association for Information Systems 11 (10): 519-549.

Cho, Y. J., and J. W. Lee. 2011. "Perceived Trustworthiness of Supervisors, Employee Satisfaction and Cooperation." Public Management Review 13 (7): 941-965. doi:10.1080/ 14719037.2011.589610.

Cho, Y. J., and H. Park. 2011. "Exploring the Relationships among Trust, Employee Satisfaction, and Organizational Commitment.” Public Management Review 13 (4): 551-573. doi:10.1080/ 14719037.2010.525033.

Cho, Y. J., and T. H. Poister. 2013. "Human Resource Management Practices and Trust in Public Organizations.” Public Management Review 15 (6): 816-838. doi:10.1080/ 14719037.2012.698854.

Das, J., C. DiRienzo, and J. Burbridge. 2010. "Global E-Government and the Role of Trust: A Cross Country Analysis.” International Journal of Electronic Government Research 5 (1): 1-18. doi:10.4018/jegr.2009010101.

Dashti, A., I. Benbasat, and A. Burton-Jones. 2009. "Developing Trust Reciprocity in ElectronicGovernment: The Role of Felt Trust." European and Mediterranean Conference on Information Systems, 13-14 $4^{\text {th }}$ July, Izmir.

Dawes, S. S. 2008. "The Evolution and Continuing Challenges of E-Governance." Public Administration Review 68: s86-s102. doi:10.1111/puar.2008.68.issue-s1.

Dwivedi, Y. K., M. Janssen, E. Slade, N. P. Rana, V. Weerakkody, J. Millard, A. J. H. Hidders, and D. Snijder. 2016b. "Driving Innovation through Big Open Linked Data (BOLD): Exploring Antecedents Using Interpretive Structural Modelling." Information Systems Frontiers. doi:10.1007/s10796-016-9675-5.

Dwivedi, Y. K., M. A. Shareef, A. C. Simintiras, B. Lal, and V. Weerakkody. 2016a. "A Generalised Adoption Model for Services: A Cross-Country Comparison of Mobile Health (M-Health)." Government Information Quarterly 33 (1): 174-187. doi:10.1016/j.giq.2015.06.003.

Dwivedi, Y. K., D. Wastell, S. Laumer, H. Z. Henriksen, M. D. Myers, D. Bunker, A. Elbanna, M. N. Ravishankar, and S. C. Srivastava. 2015. "Research on Information Systems Failures and Successes: Status Update and Future Directions." Information Systems Frontiers 17 (1): 143157. doi:10.1007/s10796-014-9500-y.

Gefen, D. 2002. "Customer Loyalty in E-Commerce." Journal of the Association of Information Systems 3 (1): 27-51.

Gil-García, J. R., and T. A. Pardo. 2005. "E-Government Success Factors: Mapping Practical Tools to Theoretical Foundations." Government Information Quarterly 22 (2): 187-216. doi:10.1016/j. giq.2005.02.001.

Grimmelikhuijsen, S. G., and A. J. Meijer. 2014. "Effects of Transparency on the Perceived Trustworthiness of a Government Organization: Evidence from an Online Experiment." Journal of Public Administration Research and Theory 24 (1): 137-157. doi:10.1093/jopart/mus048.

Hibbing, J. R., and E. Theiss-Morse. 2001. "Introduction: Studying the American People's Attitudes toward Government, When Do Americans Tend to Be Dissatisfied with Government." In What Is It about Government that Americans Dislike? Eds. J. R. Hibbing and E. Theiss-Morse, 1-7. Cambridge: Cambridge University Press.

Hong, H. 2013. "Government Websites and Social Media's Influence on Government-Public Relationships.” Public Relations Review 39 (4): 346-356. doi:10.1016/j.pubrev.2013.07.007.

Horst, M., M. Kuttschreuter, and J. M. Gutteling. 2007. "Perceived Usefulness, Personal Experiences, Risk Perception and Trust as Determinants of Adoption of E-Government Services in the Netherlands." Computers in Human Behavior 23 (4): 1838-1852. doi:10.1016/j.chb.2005.11.003.

Hughes, D. L., Y. K. Dwivedi, N. P. Rana, and A. C. Simintiras. 2016. “Information Systems Project Failure - Analysis of Causal Links Using Interpretive Structural Modelling.” Production Planning \& Control 27: 1313-1333. doi:10.1080/09537287.2016.1217571.

Karavasilis, I., Zafiropoulos, K., and Vrana V. 2010. "Extending TAM to Understand EGovernance Adoption by Teachers in Greece.” In WSKS 2010, Part II, CCIS 112, edited by 
M. D. Lytras, P. Ordonez de Pablos, A. Ziderman, A. Roulstone, H. Maurer, and J.B. Imber, 57-68. Berlin: Springer.

Lal, R., and A. Haleem. 2009. "A Structural Modelling for E-Governance Service Delivery in Rural India." International Journal of Electronic Governance 2 (1): 3-21. doi:10.1504/ IJEG.2009.024962.

Lee, J., and H. R. Rao. 2009. “Task Complexity and Different Decision Criteria for Online Service Acceptance: A Comparison of Two E-Government Compliance Service Domains." Decision Support Systems 47 (4): 424-435. doi:10.1016/j.dss.2009.04.009.

Levi, M., and L. Stoker. 2000. "Political Trust and Trustworthiness." Annual Review of Political Science 3 (1): 475-507. doi:10.1146/annurev.polisci.3.1.475.

Mandal, A., and S. G. Deshmukh. 1994. "Vendor Selection Using Interpretive Structural Modelling (ISM)." International Journal of Operations and Production Management 14 (6): 52-59. doi:10.1108/01443579410062086.

Margetts, H. 2011. “The Internet and Transparency." The Political Quarterly 82 (4): 518-521. doi:10.1111/poqu.2011.82.issue-4.

Mayer, R. C., J. H. Davis, and F. D. Schoorman. 1995. “An Integrative Model of Organizational Trust." Academy of Management Review 20 (3): 709-734.

McKnight, D. H., V. Choudhury, and C. Kacmar. 2002. "Developing and Validating Trust Measures for E-Commerce: An Integrative Approach.” Information Systems Research 13 (3): 334-359. doi:10.1287/isre.13.3.334.81.

Morgeson, I. I. I., F. V. D. VanAmburg, and S. Mithas. 2011. "Misplaced Trust? Exploring the Structure of the E-Government-Citizen Trust Relationship." Journal of Public Administration Research and Theory 21 (2): 257-283. doi:10.1093/jopart/muq006.

Nachmias, D. 1985. "Determinants of Trust with the Federal Bureaucracy." In Public Personnel Policy: The Politics of Public Service, ed. D. H. Rosenbloom, 133-143. Port Washington, NY: Associated Faculty.

Parasuraman, A., V. Zeithaml, and L. Berry. 1988. "SERVQUAL: A Multiple-Item Scale for Measuring Consumer Perceptions of Service Quality.” Journal of Retailing 64 (1): 12-40.

Parent, M., C. A. Vandebeek, and A. C. Gemino. 2005. "Building Citizen Trust through E-Government." Government Information Quarterly 22 (4): 720-736. doi:10.1016/j. giq.2005.10.001.

Park, H., and J. Blenkinsopp. 2011. "The Role of Transparency and Trust in the Relationship between Corruption and Citizen Satisfaction." International Review of Administrative Sciences 77 (2): 254-274. doi:10.1177/0020852311399230.

Rana, N. P., and Y. K. Dwivedi. 2015. “Citizen's Adoption of an E-Government System: Validating Extended Social Cognitive Theory (SCT).” Government Information Quarterly 32 (2): 172-181. doi:10.1016/j.giq.2015.02.002.

Rana, N. P., Y. K. Dwivedi, B. Lal, M. D. Williams, and M. Clement. 2015a. "Citizens' Adoption of an Electronic Government System: Towards a Unified View.” Information Systems Frontiers 1-20. http://link.springer.com/article/10.1007/s10796-015-9613-y.

Rana, N. P., Y. K. Dwivedi, and M. D. Williams. 2015b. "A Meta-Analysis of Existing Research on Citizen Adoption of E-Government.” Information Systems Frontiers 17 (3): 547-563. doi:10.1007/ s10796-013-9431-z.

Rana, N. P., Y. K. Dwivedi, M. D. Williams, and V. Weerakkody. 2016. “Adoption of Online Public Grievance Redressal System in India: Toward Developing a Unified View." Computers in Human Behavior 59: 265-282. doi:10.1016/j.chb.2016.02.019.

Ravishankar, M. N. 2013. "Public ICT Innovations: A Strategic Ambiguity Perspective." Journal of Information Technology 28 (4): 316-332. doi:10.1057/jit.2013.18.

Robinson, S. E., X. Liu, J. W. Stoutenborough, and A. Vedlitz. 2013. "Explaining Popular Trust in the Department of Homeland Security." Journal of Public Administration Research and Theory 23 (3): 713-733. doi:10.1093/jopart/mus025.

Rosenstone, S. J., and M. Hansen. 1993. Mobilization, Participation, and Democracy in America. New York, NY: Macmillan.

Ruscio, K. P. 1996. “Trust, Democracy, and Public Management: A Theoretical Argument.” Journal of Public Administration Research and Theory 6 (3): 461-477. doi:10.1093/oxfordjournals.jpart. a024321. 
Sage, A. P. 1977. Interpretive Structural Modelling: Methodology for Large Scale Systems, 91-164. New York, NY: McGraw-Hill.

Sandeep, M. S., and M. N. Ravishankar. 2014. "The Continuity of Underperforming ICT Projects in the Public Sector." Information and Management 51 (6): 700-711. doi:10.1016/j. im.2014.06.002.

Schaupp, L. C., and L. Carter. 2010. "The Impact of Trust, Risk and Optimism Bias on E-file Adoption." Information Systems Frontiers 12 (3): 299-309. doi:10.1007/s10796-008-9138-8.

Shareef, M. A., N. Archer, and Y. K. Dwivedi. 2015. "An Empirical Investigation of Electronic Government Service Quality: From the Demand Side Stakeholder Perspective.” Total Quality Management \& Business Excellence 26 (3-4): 339-354. doi:10.1080/14783363.2013.832477.

Shareef, M. A., Y. K. Dwivedi, V. Kumar, and U. Kumar. 2016a. "Reformation of Public Service to Meet Citizens' Needs as Customers: Evaluating SMS as an Alternative Service Delivery Channel." Computers in Human Behavior 61: 255-270. doi:10.1016/j.chb.2016.03.002.

Shareef, M. A., Y. K. Dwivedi, S. Laumer, and N. Archer. 2016b. "Citizens' Adoption Behavior of Mobile-Government (Mgov): A Cross-Cultural Study.” Information Systems Management 33 (3): 268-283. doi:10.1080/10580530.2016.1188573.

Shareef, M. A., Y. K. Dwivedi, T. Stamati, and M. D. Williams. 2014. "SQ Mgov: A Comprehensive Service-Quality Paradigm for Mobile Government." Information Systems Management 31 (2): 126-142. doi:10.1080/10580530.2014.890432.

Shareef, M. A., V. Kumar, U. Kumar, and Y. K. Dwivedi. 2011. "E-Government Adoption Model (GAM): Differing Service Maturity Levels.” Government Information Quarterly 28 (1): 17-35. doi:10.1016/j.giq.2010.05.006.

Singh, R. K., S. K. Garg, and S. G. Deshmukh. 2007. "Interpretive Structural Modelling of Factors for Improving Competitiveness of Smes." International Journal of Productivity and Quality Management 2 (4): 423-440. doi:10.1504/IJPQM.2007.013336.

Smith, M. L. 2010. "Building Institutional Trust through E-Government Trustworthiness Cues." Information Technology \& People 23 (3): 222-246. doi:10.1108/09593841011069149.

Smith, M. L. 2011. "Limitations to Building Institutional Trustworthiness through E-Government: A Comparative Study of Two E-Services in Chile." Journal of Information Technology 26 (1): 78-93. doi:10.1057/jit.2010.17.

Talib, F., Z. Rahman, and M. N. Qureshi. 2011a. “An Interpretive Structural Modelling Approach for Modelling the Practices of Total Quality Management in Service Sector.” International Journal of Modelling in Operations Management 1 (3): 223-250. doi:10.1504/IJMOM.2011.039528.

Talib, F., Z. Rahman, and M. N. Qureshi. 2011b. "Analysis of Interaction among the Barriers to Total Quality Management Implementation Using Interpretive Structural Modeling Approach.” Benchmarking: An International Journal 18 (4): 563-587. doi:10.1108/14635771111147641.

Tan, C. W., I. Benbasat, and R. T. Cenfetelli. 2008. "Building Citizen Trust Towards E-Government Services: Do High Quality Websites Matter?" $41^{\text {st }}$ Hawaii International Conference on Systems Sciences, $7-10^{\text {th }}$ January, Waikoloa.

Teo, T. S. H., S. C. Srivastava, and L. Jiang. 2008. "Trust and Electronic Government Success: An Empirical Study.” Journal of Management Information Systems 25 (3): 99-132. doi:10.2753/ MIS0742-1222250303.

Tolbert, C., and K. Mossberger. 2006. "The Effects of E-Government on Trust and Confidence in Government." Public Administration Review 66 (3): 354-369. doi:10.1111/puar.2006.66.issue-3.

van Ryzin, G. G., D. Muzzio, S. Immerwahr., L. Gulick, and E. Martinez. 2004. "Drivers and Consequences of Citizen Satisfaction: An Application of the American Customer Satisfaction Index Model to New York City." Public Administration Review 64 (3): 331-341. doi:10.1111/ puar.2004.64.issue-3.

Vigoda-Gadot, E. 2007. “Citizens' Perceptions of Politics and Ethics in Public Administration: A Five-Year National Study of Their Relationship to Satisfaction with Services, Trust in Governance, and Voice Orientations." Journal of Public Administration Research and Theory 17 (2): 285-305. doi:10.1093/jopart/muj018.

Vigoda-Gadot, E., and F. Yuval. 2003. "Managerial Quality, Administrative Performance and Trust in Governance Revisited." The International Journal of Public Sector Management 16 (7): 502522. doi:10.1108/09513550310500382. 
Wang, X. H., and M. Wan Wart. 2007. "When Public Participation in Administration Leads to Trust: An Empirical Assessment of Managers' Perceptions.” Public Administration Review 67 (2): 265-278. doi:10.1111/j.1540-6210.2007.00712.x.

Warfield, J.W. 1974. "Developing Interconnected Matrices in Structural Modelling." IEEETranscript on Systems, Men and Cybernetics 4 (1): 81-87.

Weare, C. 2002. "The Internet and Democracy: The Causal Links between Technology and Politics." International Journal of Public Administration 25 (5): 659-691. doi:10.1081/PAD-120003294.

Welch, E. W., C. C. Hinnant, and M. J. Moon. 2005. "Linking Citizen Satisfaction with E-Government and Trust in Government." Journal of Public Administration Research and Theory 15 (3): 371-391. doi:10.1093/jopart/mui021.

West, D. M. 2005. Government: And Digital Technology Public-Sector Performance. Princeton, NJ: Princeton Press.

Yang, K., and L. G. Anguelov. 2013. "Trustworthiness of Public Service." In Public Administration Reform: Market Demand from Public Organizations, edited by Y. K. Dwivedi, M. A. Shareef, S. K. Pandey, and V. Kumar, 59-75. New York, NY: Routledge. 


\section{Appendix [A]: Constructs' definitions and relationship matrix used for ISM survey}

NB: Please remember to consider these constructs from the perspective of citizens.

[1] Trust of government - Belief that government will behave as expected in a socially responsible manner; [2] Trust of Internet - Belief that the Internet will behave as expected in a socially responsible manner; [3] Disposition to trust - The extent to which an individual displays an inclination to trust others; [4] Perceived risk - Feelings of uncertainty or anxiety about the behaviour and seriousness of the possible outcomes; [5] Privacy concerns - The inhibitors of disclosing personal information; [6] Perceived security - Perceived protection from any type of financial or non-financial risk; [7] Political attitudes - Acitizen's political orientation; [8] Transparency - Availability of information about the internal workings or performance of government; [9] Perceived prior knowledge - Newness of information disclosed to a citizen; [10] Accountability - The answerability of government to the public on e-government services performance; [11] Responsiveness - The level of convenience or degree of immediate feedback provided, usually to resolve a problem; [12] Service quality - Attitudes towards the level of service provided by e-government; [13] Satisfaction - Level of contentment regarding e-government services; [14] System quality - Attitudes towards the level of quality of the e-government systems; [15] Perceived ability to use - Personal judgements of the possession of skills required to use a technology; [16] Use - Citizens' use of e-government; [17] Benevolence - Degree to which citizens believe that egovernment cares about them and want to help them; [18] Integrity - Degree to which citizens believe that e-government adheres to standards and principles that the public find acceptable; [19] Competence - Degree to which e-government possess the skills needed to enable it to perform its tasks in serving the public; [20] Trustworthiness of e-government - Characteristics of e-government that may generate citizens' trust.

Table A1. Relationship matrix used for survey.

\begin{tabular}{|c|c|c|c|c|c|c|c|c|c|c|c|c|c|c|c|c|c|c|c|c|}
\hline $\mathrm{VR}[\mathrm{i} / \mathrm{j}]$ & 20 & 19 & 18 & 17 & 16 & 15 & 14 & 13 & 12 & 11 & 10 & 9 & 8 & 7 & 6 & 5 & 4 & 3 & 2 & 1 \\
\hline 1 & & & & & & & & & & & & & & & & & & & & \\
\hline 2 & & & & & & & & & & & & & & & & & & & & \\
\hline 3 & & & & & & & & & & & & & & & & & & & & \\
\hline 4 & & & & & & & & & & & & & & & & & & & & \\
\hline 5 & & & & & & & & & & & & & & & & & & & & \\
\hline 6 & & & & & & & & & & & & & & & & & & & & \\
\hline 7 & & & & & & & & & & & & & & & & & & & & \\
\hline 8 & & & & & & & & & & & & & & & & & & & & \\
\hline 9 & & & & & & & & & & & & & & & & & & & & \\
\hline 10 & & & & & & & & & & & & & & & & & & & & \\
\hline 11 & & & & & & & & & & & & & & & & & & & & \\
\hline 12 & & & & & & & & & & & & & & & & & & & & \\
\hline 13 & & & & & & & & & & & & & & & & & & & & \\
\hline 14 & & & & & & & & & & & & & & & & & & & & \\
\hline 15 & & & & & & & & & & & & & & & & & & & & \\
\hline 16 & & & & & & & & & & & & & & & & & & & & \\
\hline 17 & & & & & & & & & & & & & & & & & & & & \\
\hline 18 & & & & & & & & & & & & & & & & & & & & \\
\hline 19 & & & & & & & & & & & & & & & & & & & & \\
\hline 20 & & & & & & & & & & & & & & & & & & & & \\
\hline
\end{tabular}

[Legend: 1 = Trust in Government, $2=$ Trust in Technology, $3=$ Disposition to Trust, $4=$ Perceived Risk, $5=$ Privacy Concerns, $6=$ Perceived Security, $7=$ Political Attitudes, $8=$ Transparency, $9=$ Perceived Prior Knowledge, 10 = Accountability, $11=$ Responsiveness, $12=$ Service Quality, $13=$ Satisfaction, $14=$ System Quality, $15=$ Perceived Ability to Use, $16=$ Use, $17=$ Benevolence, $18=$ Integrity, $19=$ Competence, $20=$ Trustworthiness of E-Government, $V R=$ Variable, $\mathrm{i}=$ row, $\mathrm{j}=$ column] 